\title{
Innovation through Urban Diversity and Achieving Comprehensive Sustainable Urbanism from a Community-Oriented Approach
}

\author{
Ali Cheshmehzangi ${ }^{1,2}$, Hei Men Aurelia Li ${ }^{3}$ \\ ${ }^{1}$ Department of Architecture and Built Environment, The University of Nottingham, Ningbo, China \\ ${ }^{2}$ Centre for Sustainable Energy Technologies, The University of Nottingham, Ningbo, China \\ ${ }^{3}$ Sustainable Design Committee, Ronald Lu and Partners Hong Kong Limited, Hong Kong, China \\ Email: *Ali.Cheshmehzangi@nottingham.edu.cn
}

How to cite this paper: Cheshmehzangi, A., \& Li, H. M. A. (2020). Innovation through Urban Diversity and Achieving Comprehensive Sustainable Urbanism from a Community-Oriented Approach. Current Urban Studies, 8, 222-240.

https://doi.org/10.4236/cus.2020.82012

Received: April 29, 2020

Accepted: May 16, 2020

Published: May 19, 2020

Copyright ( 2020 by author(s) and Scientific Research Publishing Inc. This work is licensed under the Creative Commons Attribution International License (CC BY 4.0).

http://creativecommons.org/licenses/by/4.0/

\begin{abstract}
In current urban studies focused on pathways of sustainable urbanism, the main discourse is on the development of all-inclusive approaches or comprehensive methods that could encompass multiple factors of sustainability. As a result, a bigger emphasis has been given to other dimensions of "cultural" or "governance" (also known as institutional). In more recent years, more scholarly research studies refer to governance as the fourth pillar of sustainability, and more research studies analyse the multi-dimensional methods of socio-cultural, socio-economic, etc. These factors all have major impacts on the social, environmental, and economic aspects of the city. As a result, this research study aims to test the notion of "sustainable urbanism" from a behavioural perspective, which includes market development behavior and political economy (or mixed economy). This study promotes urban diversity from the multiplicity of diversity across the physical environment, social and economic systems, cultural attributes, people backgrounds, professions and sectors, etc. This then leads to discussions on innovation through urban diversity. Hence, it is important to evaluate how diversity promotes sustainable urbanism through specific economic and social systems in contemporary city development scenarios. The findings from this study feed into matters of urban diversity and urban innovation, and towards pathways of sustainable urbanism.
\end{abstract}

\section{Keywords}

Diversity, Urban Diversity, Sustainable Urbanism, Urban Innovation, Economic 
and Social Systems

\section{Introduction}

Globalisation is not merely the result of an economic process, but indeed, is considered as a trigger point of creating a paradox in the urban context (Adekola and Sergi, 2007; Rushing, 2009; Millott and Tournois, 2010); a set of events and cultures that confront and link with each other. These include spatial matters, social and economic factors, as well as cultural factors. Some of these trends appear as transformative processes that may, in fact, change the overall image, values, and characteristics of the urban context. The current globalisation movement tends to lead towards two major development patterns. Firstly, cities will develop by the continuing globalisation-or often considered as Americanisation-trend and people will be interpreted as consumers rather than citizens while the city will act as a commodity to be consumed; ignoring the distinctions of cities in redevelopment, the images of cities will be standardised and merged as a whole. In this way, cities will form commonalities that shape their common identity (Cheshmehzangi, 2020) through characteristics, certain values, images, and other factors. These could be evaluated from socio-spatial considerations and how our interrelationships with the surroundings may show a certain level of commonalities with other places and spatial configurations (Cheshmehzangi and Heath, 2012). Secondly, cities will anticipate hybrid and mixture of world cultural elements and traditions. This means a combined effect that may include some of those commonalities but could also show a hybrid model or even a distinctive one, too. Nevertheless, in the current rapid process of globalisation, sustainability is only employed to achieve economic growth. Thus, the development considerate solely for economic reasons is in conflicts with the social and environmental aspects of our contemporary developments and cities. This also means a possibility for new modes of development (Xie et al., 2020) and pathways that suggest new modes of identity-relations (Cheshmehzangi, 2014), socio-economic values, socio-cultural attributes, etc.

A major factor in this globalisation trend is the method of achieving sustainability, for instance from the perspective of sustainable urbanism. A comprehensive approach to sustainable urbanism would include the fourth dimension of either cultural (Hawkes, 2001; Cheshmehzangi et al., 2010), or institutional/governance (Spangenberg et al., 2002; Komeily \& Srinivasan, 2015; Dawodu et al., 2016). In the former (Figure 1), the cultural dimension is added to represent the importance of quality of life. This considered from an array of values, aspirations, relationships, diversity, creativity, innovation, and vitality. This is added to the traditional dimensions of sustainability, namely social, economic, and environmental. In the latter example (Figure 2), we see the four dimensions shaping in various forms of point, Linear, and planar considerations (Valentin and 


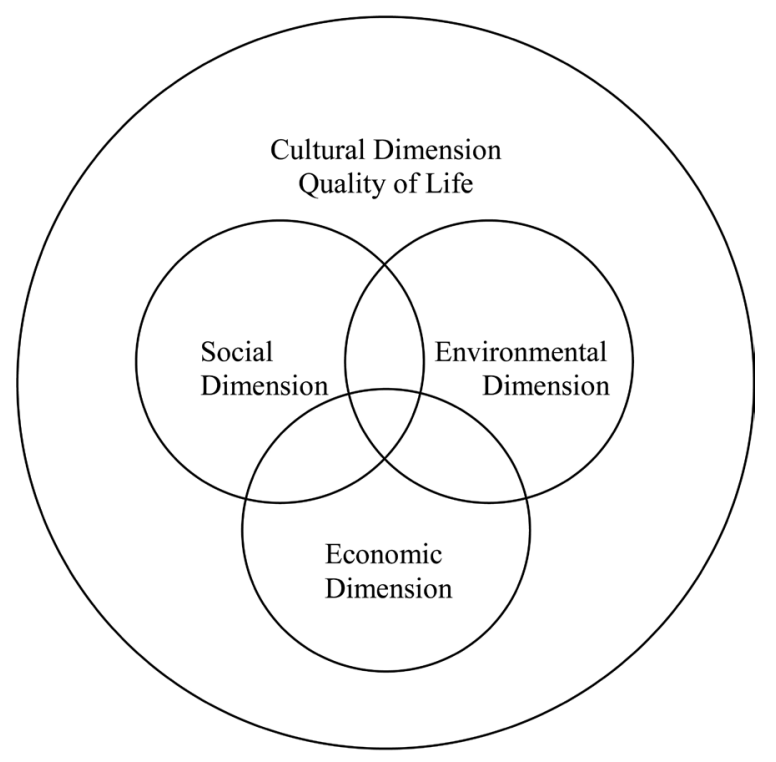

Figure 1. The four interlinked dimensions of sustainability: "Cultural Dimension and Quality of Life” (adapted and redrawn from Hawkes, 2001, available from http://www.computingforsustainability.com).



Environmental Imperative

Figure 2. Representation of four pillars of sustainability (adapted and redrawn from Valentin and Spangenberg, 2000 and Dawodu et al., 2016).

Spangenberg, 2000). In this approach, dimensions seem to be more of the imperative aspects that are related and co-exist with one another.

Of all globalisation trends, this study evaluates urban diversity from the perspective of sustainable urbanism. As we see more cities and communities are becoming diverse by various means, one of which is recognised as a mixed-use development. This mode of development is considered a very common approach 
in the last few decades, and it highlights many debates from the sustainability perspective (Huston and Mateo-Babiano, 2013; Speck, 2014; Zamorano and Kulpa, 2014; Live Oak Contracting, 2015). If considered as just the physical mix, then we may not necessarily achieve a mixed-use sustainable development. But if combined with the ideals of diverse community, backgrounds, economies, sectors, the likelihood for sustainable mixed-use development is quite high. This could be expressed beyond the physicality of the mixed-use development, but understanding the multiplicity of factors. In fact, this should not only use any of the two above sustainability models but rather combine them all with the added dimensions of "physical" and "health". In doing so, we propose a broader understanding of community-based development, which could be sustainable in various ways and not only based on the conventional dimensions of sustainability. This particularly addresses the comprehensiveness of sustainable urbanism, which should respond to the multiplicity of community needs and development scenarios. Furthermore, this approach enables us to detect and understand the values of sustainability for various reasons. Hence, in a comprehensive understanding of sustainable urbanism here, we could consider seven dimensions as shown here:

1) Social

2) Economic

3) Environmental

4) Cultural

5) Institutional

6) Physical

7) Health

In line with sustainability assessment studies, this study aims to identify how urban diversity could help to promote a more comprehensive sustainable urbanism. Considering the importance of each dimension on its own, it is important for us to be able to link diversity in design and planning with the ideals of sustainable development (SD). Socially, it is important to recognise what makes the urban environment sociable and community-oriented. Culturally, it is important to maintain a range of heritage, history, and local values that define the characteristics and identity of the urban environment (Cheshmehzangi, 2020). Economically, we have to assess the vitality and viability of the city and its environments. Environmentally, we have to consider the values of urban ecologies, ecosystem services (if any), and environmental considerations. Based on the institutional dimension, it is important to identify the role of governance in creating a sound urban environment. Based on the physical dimension, we have to understand the design and planning aspects of the urban environment and how they fit with the concept of sustainable development. And based on the health dimension, it is vital for us to maintain the wellbeing of the communities and city environments.

Throughout major case studies in the field of diversity and creativity, this 
study aims to explore the parameters and significance of diversity in design and their implications for a holistic approach towards achieving sustainable urban developments. This study aims to elaborate on the complications as well the potentials in diverse societies and communities and how designers and planners can incorporate such values as major indicators to urban growth; not only economically, but also socially, environmentally, and culturally. This means, the idea of diversity is studied beyond the notion of mixed-use development and is related to the understanding of communities and how they form or should form from the multiplicity of sustainable dimensions. Finally, this study, with a holistic overview, contributed to current urban studies that are linked to various discussions or case study analysis in the fields of urban diversity, mixed-use development, creative industries, integrated design, and sustainable urbanism.

\section{Methodology}

This study is mainly conducted by desktop research and the use of available data for case study evaluation. The desktop research is based on the analysis of available data and documents, those that are available for the case study before 2004, in 2004, and afterwards. The main methods of this research are analytical study, which is based on case studies, available data, and the verification that is then done through case study reports and documents. For the case study, the study uses available data from a case of regeneration and extracts lessons learned from this particular example. The analysis uses the available data from the surveys of the case study in 2004 across multiple themes of the area. The 2004 data is mainly used as the source for the project assessment at the time of regeneration development. Also in 2004, the case study of research held the first Architecture Festival biennale, which then had a major impact on the regeneration of the area. Hence, the data of 2004 is not identified to be outdated as it represents the findings of the project impact at its crucial stage of regeneration, which are important for this study's assessment. Those themes are then used for further evaluation of sustainable development, from multiple perspectives. The evaluation is conducted by further research on the available documents on earlier development modes and projects (the 1960s till early 2000s) and more contemporary regeneration and redevelopment documents (early 2000s onwards). The data from 2004 is used mainly as the main themes of the case study and are evaluated based on the available data, with cross-referencing to some of these documents. The later documents after 2004 are also assessed through desktop research to ensure validity and continuation of the results from 2004 onwards.

\section{A Brief Literature Review: The Sustainable Evolution and the City}

All life forms on the planet are part of the same, complex, and mutually interdependent ecosystem (Willis, 1997; Chapin et al., 2002; Krebs, 2009). Hence, by referring to the natural ecosystem, we can identify two forms of sustainability. 
The two forms are either considered as sustainability to be achieved by matching the ecological niche and the organism, or through flexibility and adaptations. We can argue that humans have evolved over the past million years in order to survive the greatest variations of environmental conditions as well as changing those environments in order to suit their needs. The success of survival in human generations is clearly shown in the ability to change and adapt to the surrounding conditions. As suggested by Wilson (1992), there is a current orthodoxy that the basis of the resilience of an ecosystem lays in its diversity. The sustainable evolution of cities is, therefore, a more relevant concept in the discussion of future development of the cities. This could be seen from the perspectives of city enhancement as well as the opportunity to evolve cities in a sustainable form that could respond to the needs of its people and communities.

Although it is obvious that the application of diversity is one of the most important factors in contemporary city planning, diversity is still poorly defined in the fields of design and urbanism. This is associated with the concept of mixed-use development but is recognised beyond the physicality of the place. Hence, by definition, diversity should not only be a mere description of the physical properties of an urban form but also the socio-economic, cultural, and perceptual qualities of the place (Cheshmehzangi, 2020). This is related to a comprehensive understanding of the urban context, which represents more than just the physical form. For the design of diversity to become meaningful, it should certainly include awareness of the static to dynamic morphology, historical considerations over time as well as personal experiences through spaces. Since diversity performs as an important role, especially under rapidly changing environments, the cost for maintenance can be interpreted as the cost for maintaining the efficiency of the population. As a result, diversity allows a sustainable development to happen, in which the social, economic, and environmental structures can work together as a whole in the urban context. Referring to Jane Jacob's (1969) comparison studies between "company town" of Manchester and "craftsman town" of Birmingham, we can identify how dependent one industry might lead to the economic collapse while the presence and application of diversity in trades allowed Birmingham to change and survive, which then led to city's revitalisation as a whole.

The senses of diverse experiences in the urban landscape create a delightful range of physical and spatial qualities to the citizens. The dimensions of streets, buildings, materials, and construction details all contribute as the key factors of our experience in the urban diversity; however, the physical and architectural quality is inadequate to account for a diverse urban environment. A diverse architectural fabric is not sufficient to provide a diverse urban environment. To be experientially diverse, the city must have a diverse cultural and social life as well as having an economic diversity. Sensory experiences like sight, sound, smell, and touch also support society in creating a diverse lifestyle. Such applications of creating a sensory urban experience will maintain the strengths and possibilities 
for growth in urban environments. One of the greatest examples is Brick Lane, London, where diversity in industries, communities, and activities promote a great sense of wholeness, while they all remain different from one another. The urban experience from such an urban district is enjoyable for visitors, while people can maintain their local economies and their interlocked communities within a chain of integrated environments.

\section{Mixed-Use Development and Pattern of Land-Use}

The concept of ecology is composed of a structured system of inter-related organisms that are interdependent with each other (Molles, 1999). In the argument of whether diversity is equal to "mixing", the answer would be that a diverse urban space is composed of more structured forms and uses rather than unsystematic, or even considerably random, mixings. The sociological interpretation suggests that diversity is a property of an organic social form, and comprises the set of inter-relations between divisions of labour, along with the efficiencies derived from all these.

In order to examine the relationships between the diversity of the urban system and its impacts on the social and economic of the urban environment, it is important to understand and verify how urban physical and spatial patterns relate to social and economic systems. According to William Alonso's development on Von Thunen's theory of central spaces (Alonso, 1964), the rent of land and cost for transportation are linked together and it should be decided where to locate particular activities accordingly. The result is that the land-use pattern centered in the central business district consists of a concentric set of rings to reduce rent-producing land-uses. Therefore, the advantages of aggregation must outweigh the disadvantages of competition from one's neighbor. On the other hand, intelligibility can be interpreted as the systematic relationship between an individual's perceptual environment and those affordances of the environment outside their immediate perception; meaning that urban environments are systematized towards a particular diversity that can bring about a particular landuse and behavioural pattern in the urban context. This is also seen in transit-oriented development that suggests a sustainable land-use plan as well as a coordination system and integration into other sustainability strategies (Liang et al., 2020). In this regard, an urban planning approach is seen to be based on multiple aspects of development, particularly if to be seen and evaluated for the approach to sustainable development.

The role of diversity in urban environments is a response to the deficiencies of zoning methods in planning and is different from the concept of "mixed-use zoning" (Fiske, 2019). In terms of sustainable development ideals, there are overlaps with mixed-use development and diversity in design (Adams, 2017) that could suggest placemaking strategies (Blackson, 2013), diverse development and planning, diverse layout and configuration, and diverse design. Yet, a sound diverse community or urban environment should also include diverse back- 
grounds of people from multiple professions/sectors, economic backgrounds, ethnicities, talents, etc. In an ideal way, such diversity could create more than just a mixed-use of buildings, places, and sectors. We could then argue how these could be integrated into the urban environment over a course of time, and how they should be perceived and adapted at a gradual pace. From the consideration of morphology (Sadeghi and Li, 2019) to ideals of sustainable urbanism, diversity plays a major role in not only enhancing mixed-use development but also the opportunity to attract creative industries, diverse backgrounds, and healthier communities. This study focuses on the combination of the two, both from the mixed-use development mode and the idea of a diverse community. This is discussed by learning from case studies, such as VivaCity2020 programme in London, and other similar examples in Canada and the U.S. The discussions provide knowledge on diversity in design and future directions on diversity in sustainable urbanism.

\section{Learning from the Case of VivaCity2020 Programme, Clerkenwell, London}

For this study, we evaluate one specific visualization tool that offers virtual $2 \mathrm{D}$ and 3D environmental analysis/assessment by implementing technologies such as aerial maps and masterplans of the areas in order to develop a framework for the spatial understanding of the city. This application would then identify particular social and financial challenges in selected areas and also emphasises upon the impacts for future developments, if to be considered as part of the urban growth or redevelopment. This tool is also pertained to as an "urban regeneration $3 D$ visualisation too", which is mainly used as a tool for visualisation of performance indicators in the urban context (Zhang, 2005). Also, the greatest goal of VivaCity2020 programme is to comprehend both the dwellers' and city developers' daily activities and their requirements for "accurate and relevant information, which is often quite difficult to access, if it exists at alp' (ibid). This $3 \mathrm{D}$ visualisation toolkit is, therefore, developed to support designers and planners to explore urban sustainability and diversity issues.

The project was carried out in London Clerkenwell, undertaken by Cities Institute at "LondonMet", and put diversity in the test by using observations and computer simulations. The key research is to test its accessibility to a larger scale. Analysis suggests that the survival of urban diversity over time depends on its lack of intelligibility. There is a predominant division between a residential North and a more commercial South. Also, there is an almost direct relationship between a land-use distribution and the urban grid configuration. Retail streets are part of areas with a denser and more intensified local grid (Perdikogianni and Penn, 2005; Zhang, 2005). The fragmentation of the area and the marginal economic status appeared to be the main survival reason in the face of wholesale development. For Clerkenwell, the role of urban diversity lies in resilience more than efficiency. The wholesale redevelopment will be driven by economic or so- 
cial motivations. In this case, it might deliver a highly efficient solution; but by doing so, it reduces the diversity of other social and cultural aspects.

From the mapping analysis study, the VivaCity 2020 Toolkit provides a 3D map of the studied area by identifying land-use diversity. The maps are generated based on diverse land-uses, and through a floor-by-floor assessment. This study provides individual 3D visualizations of all floors, which include an array of land-uses, such as agricultural, community facilities, industrial, car parks, education, leisure, catering, emergency services, medical facilities, commercial/office, hotels, and open public spaces. The visualized maps also include other key sectors such as residential, transport, retail, services, and storage. They also include those areas that are under construction, underdeveloped land, and vacant premises. The policy and planning implications for the management of such a regeneration zone are examined by (Aiesha and Evans, 2006). This method is then used as part of urban design decision making (Cooper and Boyko, 2010), which response to sustainable development ideals of the urban design process. The mixed-use development approach then helps to consider a step-bystep process in developing people-oriented communities and those that could address multiple aspects of sustainable urbanism. In doing so, VivaCity 2020 provided an opportunity to visualize what is on the ground and how it could be changed in a process that comprises adequate planning and design measures. By learning from this specific programme, we see an early innovative approach that suggested the possibility of multi-perspectives and multi-dimensions. Here, this example represents a model of innovation that promotes urban diversity not only through uses and the physicality but also from the people's dimension.

Hosting London's first Architecture Festival biennale in 2004, Clerkenwell represents a unique example of regeneration from a mixed-use development that promotes diversity and creativity. The survey of 2004 from the London Architecture Festival represented viewpoints of people living, working, and vising Clerkenwell and what they liked about the regenerated area. In 14 themes, the respondents appreciated the most range of available restaurants and bars, the atmosphere, and the history and heritage of the area. The least appreciated themes of that time were affordability, transport, and creative industries. In this study, we evaluate these 14 themes across all seven named dimensions of sustainability to see how these main themes are addressed from multiple perspectives. This evaluation helps us to understand a threefold: 1) the multiplicity of sustainability values in this regenerated area, 2) the potential correlation between what is important to people and how it is represented through the regenerated development, and 3) the relevance of these main themes across not only one dimension but multiple dimensions in sustainable urbanism. This assessment is done based on the available 14 themes of the earlier survey by the London Metropoli$\tan$ Office in 2004, as well as the available data on the earlier and recent urban regeneration projects of the area. The data is then verified through the results of 


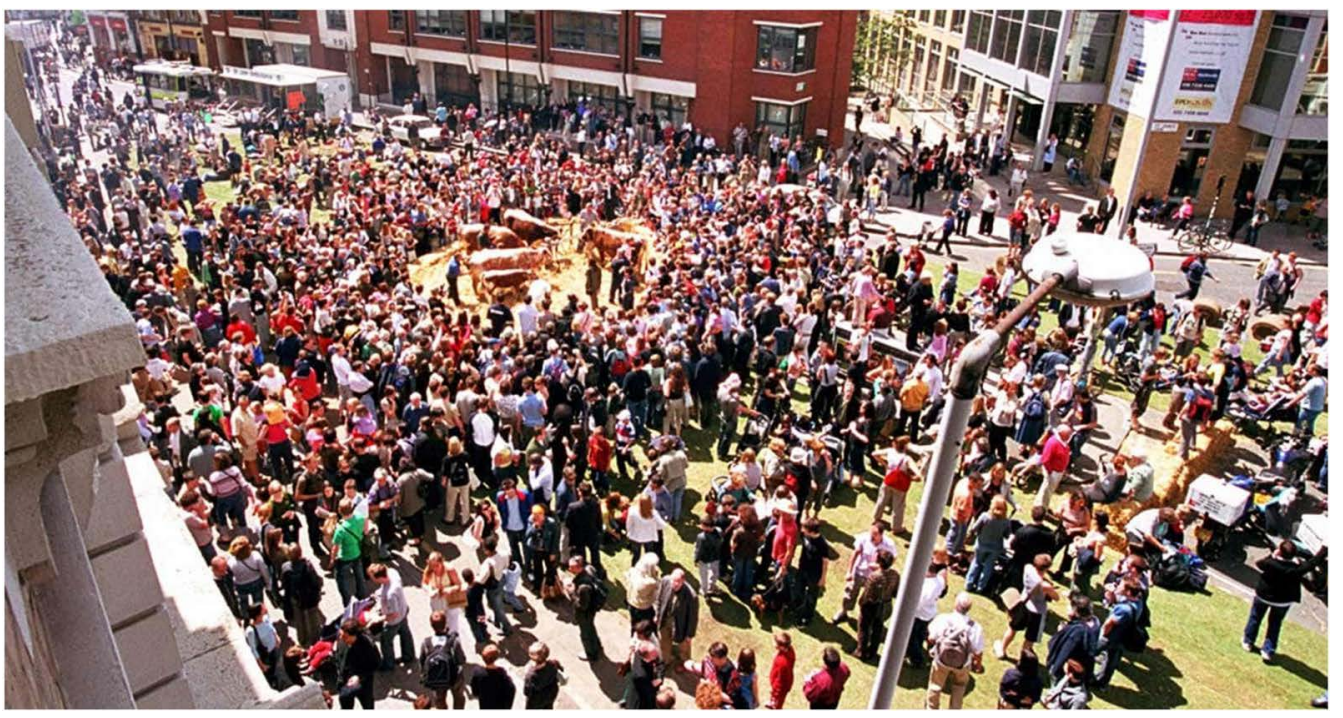

Figure 3. Founded by Peter Murray, the London Festival of Architecture is a celebratory event organised in London during a short period in summer. It started in 2004 and based around Clerkenwell, London. It started as a biennale festival till 2012 and then became an annual event in the City of London since then. The very first event as shown in this figure lasted ten days and included many lectures and talks from well-known architects, such as Zaha Hadid, Peter Ackroyd, and Dejan Sudjic. The event was oriented around the main topic of "Gentrification v Regeneration", which was also marked as an important era for the Clerkenwell area. It soon became a major attraction event that made regeneration more visible. (Source for image: from the festival archives of London Festival of Architecture (LFA), available from: https://www.londonfestivalofarchitecture.org/festivals/).

the survey as well as the mode of development that has taken place in Clerkenwell in recent decades (Figure 3).

Based on the results (summarised in Table 1), we can see a major difference between two groups of social, economic, cultural, and physical against environmental, institutional, and health. The results respond to the importance of multiple sustainable values for each theme, with a range of 3 - 5 sustainable dimensions for each theme, and an average of 4 . We also see that there are major gaps in the findings. For instance, more attention is given to physical dimension that to environmental or health dimensions, and while institutional dimension appeared the highest across all 14 themes, it also appeared as the least valued dimensions against five of them (out of 11). Also, the lack of environmental and health dimensions show a tangible gap in some of the main themes, which should be taken into consideration for future development. We also see the correlation between what is important and what is addressed in terms of sustainable development and across multiple dimensions. For instance, affordability was the least appreciated theme, while it is one of the main economic indicators. The shift to economic development, especially in the more recent two decades, suggests a transformation towards the cultural and creative part of the City of London (Hutton, 2011). This is also seen in studies of Evans (2014) who refers to Clerkenwell as a mixed-use urban village. Evans (ibid, p. 127) also argue that "the relationship between urban diversity and quality of life is a recurring 
Table 1. Assessment of 14 themes of Clerkenwell survey against seven dimensions of sustainability (Note: the normal $\checkmark$ means the relationship with the specific dimension, the bold $\checkmark$ means the highest relationship between the specific dimension and the theme, the bold $\checkmark$ means the lowest).

\begin{tabular}{|c|c|c|c|c|c|c|c|}
\hline & Social & Economic & Environmental & Cultural & Institutional & Physical & Health \\
\hline Affordability & $\checkmark$ & $\checkmark$ & & & $\checkmark$ & & \\
\hline Creative Industries & $\checkmark$ & $\checkmark$ & & $\checkmark$ & $\checkmark$ & $\checkmark$ & \\
\hline People & $\checkmark$ & & & $\checkmark$ & & & $\checkmark$ \\
\hline Atmosphere & $\checkmark$ & & $\checkmark$ & $\checkmark$ & & $\checkmark$ & $\checkmark$ \\
\hline Amenities & & & $\checkmark$ & & $\checkmark$ & $\checkmark$ & $\checkmark$ \\
\hline Mix & $\checkmark$ & $\checkmark$ & $\checkmark$ & & $\checkmark$ & $\checkmark$ & \\
\hline Streets & $\checkmark$ & & $\checkmark$ & & & $\checkmark$ & $\checkmark$ \\
\hline History and Heritage & & & $\checkmark$ & $\checkmark$ & $\checkmark$ & $\checkmark$ & \\
\hline Architecture & & & & $\checkmark$ & $\checkmark$ & $\checkmark$ & \\
\hline Vitality & $\checkmark$ & $\checkmark$ & & & $\checkmark$ & & $\checkmark$ \\
\hline Restaurants and Bars & $\checkmark$ & $\checkmark$ & & $\checkmark$ & & $\checkmark$ & \\
\hline Community & $\checkmark$ & $\checkmark$ & $\checkmark$ & $\checkmark$ & $\checkmark$ & & \\
\hline Transport & & $\checkmark$ & & & $\checkmark$ & $\checkmark$ & \\
\hline Accessibility & $\checkmark$ & $\checkmark$ & & & $\checkmark$ & $\checkmark$ & \\
\hline
\end{tabular}

assumption in mixed-use policy. However, how land-use diversity enhanced the quality of urban life is poorly understood'. In this regard, it is evident that diversity in land-use alone cannot simply address the matters of quality life in urban living. As we see from the records in Clerkenwell, the lack of creative industries and sound transport system also suggest a lack of progressive development for this particular area. More importantly, from the findings, we notice, the absence of health and environmental dimensions are also visible in the selected themes of the survey that were then used for regeneration developments. The economic focus, and partly socio-cultural values of the area, also indicate tangible gentrification that is not nurtured by creative industries but residential and real estate redevelopment projects. The proximity of Clerkenwell to the central part of the city is a major driver for the economic transformation of this important cultural quarter of the city.

In addition, as Clerkenwell's economic development has been mostly developed based on the "district's unique internal spatiality and built environment" (Hutton, 2010: p. 128), we anticipate a more perceptible emphasis on the social, economic, and cultural dimensions-or better to say, socio-cultural or socio-economic attributes of the area. This represents the space-economy of the area from the agglomeration of land-uses, primarily based on the "financial, commercial, and professional office operations" (ibid, p. 130). As part of the larger process of regeneration, there are records of reduction in greenery, and some of the actual main green areas are mostly used for other uses of perfor- 
mance, events, and exhibitions. Also, for residential aspects, the records indicate the replacement of local industries by new housing projects or refurbishment (Cherry and Pevner, 1998); some that started as early as the 1970s and then through the era of urban renaissance in the UK. This also represents an earlier transformation of this major inner-city area and from a shift towards a more economic hub through a transformation of land-uses, re-configurations, occupancy, demographics, and the larger economic landscape of Clerkenwell (Hutton, 2010).

Finally, based on the finding we see that multiple dimensions of sustainability are addressed across various themes and in different ways. While the atmosphere of Clerkenwell has been appraised due to its historical and cultural characteristics, it is seen that there are significant transformation and/or regeneration of amenities, history and heritage, architecture, and the community. Under these themes, we see the significant presence of physical dimension, through which we indicate the importance of regeneration through physical development. On the contrary, we see transport and accessibility, both with the physical dimension as their priority but still lacking the progress in comparison to the cultural development of the area. Also, as indicated earlier, the lack of environmental and health dimensions presents an opportunity for further development and a reflective approach to a more community-oriented development approach.

\section{Other Similar Studies: Diversity in the U.S. and Canadian Cities}

The theory developed by Florida and Gates (2001) suggests that a city's diversity is the key to attract talented people. In other studies, this is also seen as potential gentrification (Florida, 2013). To do so and attract talented people, Florida and Gates (2001) established three main indexes to do the measurement. The gay index measures the representation of homosexual male couples, the bohemian index measures the numbers of artists, actors, and designers, the foreign-born index measures the number of immigrants. These numbers are then summed up to produce the composite diversity index (shown as key indicators; see Table 2). Based on the 1990 census numbers for 50 largest cities in the U.S. (also for Canadian Cities in 2002), the measure of high-tech growth is regarded as an indication

Table 2. Comparing the Key Indicators in Canada and U.S.-(Source: adapted and redrawn from Florida and Gates 2001, and Gertler et al., 2002).

\begin{tabular}{ccc}
\hline & CANADA & UNITED STATES \\
\hline Population (until 2001) & $28,846,760$ & $248,709,873$ \\
Size of Largest Metropolitan Area (until 2001) & $4,263,757$ & $18,087,251$ \\
\% Talent & $13.8 \%$ & $18.5 \%$ \\
\% Foreign Born & $17.2 \%$ & $8.0 \%$ \\
Bohemians per 100 & 6.1 & 5.8 \\
\hline
\end{tabular}


of success in the future city. They then found that all the indicators show a high correlation with future high-tech growth. The diversity of human capital is, therefore, a key component of the ability to attract and retain high-tech industries (Gertler et al., 2002; Rhule, 2017). This particular approach explores cities in terms of their potential for creativity and diversity in the society that can benefit the strategies for urban growth. The relationship between technology-intensive activities, creativity, talent, and diversity as major drivers for economies (particularly the local economies) is studied and analysed to give a broad range of economic knowledge for further developments in the future regeneration or design.

By indicating and including these indexes, the researchers (Florida and Gates, 2001; Gertler et al., 2002) suggest for the role of non-physical diversity in urban development decision making. This is particularly applicable to cases of urban regeneration and large-scale redevelopment projects. This understanding of diversity beyond the physicality and configuration of the urban environments suggest the role of people in their communities, workplaces, and their immediate context (Cheshmehzangi, 2020). Similar to the earlier example of Clerkenwell, we see the opportunity to combine the ideas of diverse built environment (e.g. through mixed-use development), with diverse communities, diverse sectors/ professions, and diverse aspects of the built environment. In doing so, the pathway to reinvent urban diversity in an all-inclusive approach can be a step towards sustainable urbanism from the community-oriented approach.

\section{Discussions: Understanding the Parameters of Diversity in Design}

Diversity, as defined in this paper, can be concluded by three ideas. Firstly, diversity is not equal to "mixed-use". It requires a higher degree of structure in which it creates spatial experience while we move to pass in time. Secondly, when taking into account diversity we must consider the cognitive dimension of intelligibility. Thirdly, the production of diversity is related to time. Urban forms and spatial structures evolve as the population and economy change over the centuries. This evolution is perceptible in many cities that valued or continue to value the role of diversity in their redevelopment processes. The unpredictability has, so far, shaped the many characteristics of diversity in our cities. Changes in political decisions and economic cycles (as well as social and economic systems) have all created particular trends and diversity of everyday life (Cheshmehzangi, 2020). It is believed that land-use functions are directly linked to open space structure as well as the efficiency of goods and services. Nevertheless, the main idea of diversity is the meaningful spatial relationship when one moves and the rate of exchange with the surrounding environment that is known as "intelligibility". This learnable process is associated with different factors of the environment such as the local geometry of space and the rate of perception by the observer. In the case study of VivaCity2020, it shows that cognition and intelligibil- 
ity are informed through spatial morphology.

Our interventions in the built environment are about representation and transmission of meaningful information. However, this information is not expressed in words but perceived through our movement in the city. It is in the essence of these information and meanings carried to generate both the social and the economic behaviours that a collaborative culture takes place. Diversity in design is not necessarily the disparities we image and experience in the physical dimension of design, but is indeed a hidden, but tangible, the value in economic and social dimensions of achieving sustainable design. This requires comprehensive thinking and should aim to address the needs of the community rather than reducing the capacity of the community. It should rather appear as a major force to support a community-oriented approach, and for that innovation through diversity is a necessity. For instance, a particular market is not only consisted of different parts; but also included various social classes and small economies. By applying diversity in an urban sense, we can categorise it into three elements: 1) diversity in spatial structures, 2) diversity of ecologies, and 3) diversity in the information.

Diversity in spatial structures is achieved by a well-structured yet fragmented network that appears to be intelligible on a local scale, unintelligent and scattered on a global scale. This provides opportunities for a diversity of ecologies, with a range of social, cultural, and economic behaviours and uses. The diversity in information is where we learn through correlations through our experience in the environment. As a result, the division of labour creates a diverse social and economic organism that evolves and reproduces over time. It is by this transmission of information that maintains a rich social and cultural life that can evolve in response to changes in the environment. The diversity created is then a kind of "genetic diversity" in a socio-economic form. It is always hard to define and investigate the "mix" of the urban environment. As shown in this study, diversity is not also mixed-use development. It is defined more than the physicality of the urban environments, as such the mixed-use development. Concluding from the above discussions, it is clear that the main idea is about time and space matters. From a historical perspective, the evolution of city and life assist in understanding the present behaviour and future development needs. Diversity is, therefore, a practice that should be better understood and applied in urban planning and economic policy. The economic diversity is the least considered element in planning, yet it is the key driver and decision-maker of maintaining life quality. As a result, a "mixed economy" would be a good manifestation in providing a sustainable urban development; and ultimately, affordable business premises would be as important as affordable housing.

\section{The Limitation of Research and Recommendations to Future Research}

This research paper intends to address one important aspect of urban diversity 
in achieving sustainable urbanism. This is looked from the perspective of a community-oriented approach that suggests the multiplicity of the urban regeneration project. One case study is used to discuss this important point in the field of research. This study uses the available research materials from one event in one specific case study, which had a major impact on that specific location. This limited selection is aimed to highlight one aspect of research, which is the focus area of this paper. As a result of this selection, this research is limited to one case study only with some additional support from other examples. It is also narrated in this way to ensure the focus point is kept at the overarching topic of innovation through urban diversity. If to conduct more elaborate research on this specific topic, it is recommended to do a comparative analysis of multiple cases in the same category, which allows us to evaluate how urban diversity plays its part in regeneration development projects. However, this requires careful selection of case studies that could be comparable or at least in the same timeline. In doing so, the parameters of comparison should be selected sensibly to ensure consistency across multiple case studies. This comparison approach may also include certain limitations or deficiencies in subjective or biased comparison evaluation. Thus, an elaborate study that includes multiple cases may require further assessment and a range of comparative parameters that are beyond the scope of this research paper. It may also be beyond the scope of a short research study as it would require to consider multiple parameters for an adequate comparative evaluation. Moreover, another recommendation for future research studies is to use one case study that could be assessed throughout a longer period of time. This is likely to be more feasible than the other recommended research direction. Nevertheless, this research approach is not applicable to the selected case as the later impacts are not completely related to the 2004 event but are partially associated with that time. To do such a study by the consideration of temporal dimension, it is vital to evaluate the regeneration progression throughout multiple stages of pre-development, development, and at least two later stages (short-term and mid-to-long term) after the regeneration project. In both recommended research approaches, it is important to evaluate the role of urban diversity in both positive and negative narratives. In doing so, we could provide more enhanced research that is context-specific and is also related to other topics such as regeneration, community development (or redevelopment), and sustainable urbanism.

\section{Conclusion: Towards Sustainable Urbanism}

From the case study of VivaCity2020 and referring to the building trend nowadays, it is corroborated that "wholesale redevelopment" fails to generate diversity in the environment and creates limited development of the socio-economic uses. The spatial disintegration (or often spatial fragmentation) may prevent the area from redevelopment, but it is also this complex history that accounts for today's diversity (Perdikogianni and Penn, 2005). Referring to the traditional cities, we 
can argue that sustainability depends on the satisfying needs and desires of citizens and remaining within the carrying capacity of the local hinterlands. The successful examples that thrived through modern age are often best-facilitated expansion through trade and expression and are also able to adapt continuously to the drastically changing economic, social, and cultural situations. This idea is similar to the "knowledge economy" as it is becoming the defining paradigm of the way we live and work in the 21st century (Harrison et al., 2004; Fachinelli et al., 2014; Fan et al., 2019; Liu et al., 2019). This approach connects demands with various supplies and emphasises upon the creation of ideas. It shows, that in the case study of diversity in the U.S., the attraction of people living in the city is the most determining factor in economic success by reflecting on people and demands, as well as the linking quality of space with the overall urban success.

To conclude, this study explores the idea of applying diversity to create a sustainable urban environment towards undertaking the socio-economic dimension of sustainability. Starting with an ecological analogy, the authors assert the appliances of diversity by land-use patterns and human movement observations as the major methods for such studies or research programmes. The discussion is further supported by the Clerkenwell and the U.S. case studies that suggested the advantages of diversity applications towards achieving sustainable urbanism. Diversity is clearly a concept that ought to be reinforced in sustainable urbanism (in both planning and design), not just in the community scale but also in design for the suburban areas and extensions to the new towns. It is the interaction and exchange between these spatial, social and informational aspects of the built environment that produce the richness and diversity in everyday life; and as a result, define, re-define and ultimately reproduce genetic sustainable urban environments.

\section{Acknowledgements}

We specially thank National Natural Science Foundation of China (NSFC) for the provision of funding for two project numbers 71850410544 and 71950410760

(led by Corresponding author). This work is also supported by Ningbo Science and Technology Bureau, project code 2017A10072.

\section{Conflicts of Interest}

The authors declare no conflicts of interest regarding the publication of this paper.

\section{References}

Adams, T. (2017). Transit-Oriented Development: Mixed-Use Zoning. https://sustainablecitycode.org/brief/mixed-use-zoning-3/

Adekola, A., \& Sergi, B. S. (2007). The Significance and Paradox of Globalisation in the 21st Century: The Role of Three Major Global Institutions in Selected Areas. International Journal of Management and Enterprise Development, 4, 354-371. 
https://doi.org/10.1504/IJMED.2007.012684

Aiesha, R., \& Evans, G. (2006). VivaCity: Mixed-Use and Urban Tourism. In M. K. Smith (Ed.), Tourism, Culture and Regeneration (pp. 35-48). Wallingford: CAB International. https://www.cabdirect.org/cabdirect/abstract/20083052570 https://doi.org/10.1079/9781845931308.0035

Alonso, W. (1964). Location and Land Use. Cambridge, MA: Harvard University Press. https://doi.org/10.4159/harvard.9780674730854

Blackson, H. (2013). Don't Get Mixed Up on Mixed-Use. PlaceMakers. https://perma.cc/SPW9-Q3DH

Chapin, F. S., Matson, P. A., \& Mooney, H. A. (2002). Principles of Terrestrial Ecosystem Ecology. New York: Springer. https://doi.org/10.1007/b97397

Cherry, B., \& Pevsner, N. (1998). London 4: North (Pevsner Architectural Guides: Buildings of England). New Haven, CT: Yale University Press.

Cheshmehzangi, A. (2014). Spatial Syntagma and Identity of a Place: Sensing, Relating to, and Knowing a Place. Journal of Human Behavior in the Social Environment, 24, 799-810. https://doi.org/10.1080/10911359.2013.876377

Cheshmehzangi, A. (2020). Identity of Cities and City of Identities. Singapore: Springer. https://doi.org/10.1007/978-981-15-3963-3

Cheshmehzangi, A., \& Heath, T. (2012). Effects of Temporary Markets on Spatial Inter-Relations: A Behavioural Analysis of a Public Realm in the UK. Journal of Asian Behavioural Studies, 2, 41-52. https://doi.org/10.21834/jabs.v2i3.190

Cheshmehzangi, A., Zhu, Y., \& Li, B. (2010). Integrated Urban Design Approach: Sustainability for Urban Design. Ningbo: Proceedings of International Conference on Green Manufacturing.

Cooper, R., \& Boyko, C. (2010). VivaCity2020's Process and Tools for Urban Design Decision Making? Journal of Urbanism: International Research on Placemaking and Urban Sustainability, 3, 253-273. https://doi.org/10.1080/17549175.2010.526366

Dawodu, A., Akinwolemiwa, B., \& Cheshmehzangi, A. (2016). A Conceptual Re-Visualization of Sustainability Pathways for the Development of Neighborhood Sustainability Assessment Tools (NSATs). Sustainable Cities and Society, 28, 398-410.

https://doi.org/10.1016/j.scs.2016.11.001

Evans, G. (2014). Living in the City: Mixed Use and Quality of Life in the City. In R. Cooper, E. Burton, \& C. Cooper (Eds.), Wellbeing: A Complete Reference Guide, Wellbeing and the Environment. Chichester: John Wiley \& Sons. https://doi.org/10.1002/9781118539415.wbwell060

Fachinelli, A. C., Carrillo, F. J., \& D’Arisbo, A. (2014). Capital System, Creative Economy and Knowledge City Transformation: Insights from Bento Gonçalves, Brazil. Expert Systems with Applications, 41, 5614-5624. https://doi.org/10.1016/j.eswa.2014.02.012

Fan, P., Urs, N., \& Hamlin, R. E. (2019). Rising Innovative City-Regions in a Transitional Economy: A Case Study of ICT Industry in Cluj-Napoca, Romania. Technology in Society, 58, Article ID: 101139. https://doi.org/10.1016/j.techsoc.2019.05.003

Fiske, C. (2019). Mixed-Use Zoning: What Is It and Why Does It Matter? Northcoast Environmental Center.

https://www.yournec.org/mixed-use-zoning-what-is-it-and-why-does-it-matter/

Florida, R. (2013). Class-Divided Cities: New York Edition.

https://www.citylab.com/equity/2013/01/class-divided-cities-new-york-edition/3819/

Florida, R., \& Gates, G. (2001). Technology and Tolerance: The Importance of Diversity 
to High Technology Growth. Washington DC: The Brookings Institute.

Gertler, M. S., Florida, R., Gates, G., \& Vinodrai, T. (2002). Competing on Creativity: Placing Ontario's Cities in North American Context. A Report Prepared for the Ontario Ministry of Enterprise, Opportunity and Innovation and the Institute for Competitiveness and Prosperity.

Harrison, A., Wheeler, P., \& Whitehead, C. (2004). Distributed Workspace: Sustainable Work Environments. London: Routledge. https://doi.org/10.4324/9780203616574

Hawkes, J. (2001). The Fourth Pillar of Stability: Culture's Essential Role in Public Planning. Melbourne: Cultural Development Network and Part of University Press. http://www.culturaldevelopment.net.au/community/Downloads/HawkesJon http://TheFourthPillarOfSustainability.pdf

Huston, S., \& Mateo-Babiano, I. (2013). Vertical Mixed-Use Communities: A Solution to Urban Sustainability? Review, Audit and Developer Perspectives. Vienna, Austria: The 20th Annual European Real Estate Society Conference.

Hutton, T. (2010). The New Economy of the Inner City: Restructuring, Regeneration and Dislocation in the 21st Century Metropolis. London: Routledge.

https://doi.org/10.4324/9780203933657

Hutton, T. (2011). Cultural Production in the Transnational City. In A. C. Pratt, \& P. Jeffcutt (Eds.), Creativity, Innovation and the Cultural Economy. Routledge Studies in Global Competition, London and New York: Routledge.

Jacob, J. (1969). The Economy of Cities. New York: Vintage.

Komeily, A., \& Srinivasan, R. S. (2015). A Need for Balanced Approach to Neighborhood Sustainability Assessments: A Critical Review and Analysis. Sustainable Cities and Society, 18, 32-43. https://doi.org/10.1016/j.scs.2015.05.004

Krebs, C. J. (2009). Ecology: The Experimental Analysis of Distribution and Abundance (6th ed.). San Francisco, CA: Benjamin Cummings.

Liang, Y., Du, M., Wang, X., \& Yu, X. (2020). Planning for Urban Life: A New Approach of Sustainable Land Use Plan Based on Transit-Oriented Development. Evaluation and Program Planning, 80, Article ID: 101811.

https://doi.org/10.1016/j.evalprogplan.2020.101811

Liu, C. Y., Hu, F. Z., \& Jeong, J. (2019). Towards Inclusive Urban Development? New Knowledge/Creative Economy and Wage Inequality in major Chinese Cities. Cities, Article ID: 102385. (In Press) https://doi.org/10.1016/j.cities.2019.06.016

Live Oak Contracting (2015). Sustainable Mixed-Use Development: Designing Economically and Socially Healthy Communities. Live Oak News.

https:/liveoakcontracting.com/news/sustainable-mixed-use-development-designing-ec onomically-and-socially-healthy-communities/

Millott, E., \& Tournois, N. (2010). The Paradoxes of Globalisation. New York and London: Palgrave Macmillan.

Molles, M. C. (1999). Ecology: Concepts and Applications. Boston, MA: WCB/McGrawHill.

Perdikogianni, I., \& Penn, A. (2005). Measuring Diversity: A Multivariate Analysis of Land Use and Temporal Patterning in Clerkenwell. Proceedings of the 5th International Space Syntax Symposium, 2, 742-761.

Rhule, J. (2017). Richard Florida, the Creative Class and Gentrification, The Shifting Human City: Essay Series on Current and Future Policy Trends in Cities. https://medium.com/project-human-city/richard-florida-the-creative-class-and-gentrif 
ication-527912a71583

Rushing, W. (2009). Memphis and the Paradox of Place: Globalization in the American South. Chapel Hill, NC: University of North Carolina Press. https://doi.org/10.5149/9780807895610_rushing

Sadeghi, G., \& Li, B. (2019). Urban Morphology: Comparative Study of Different Schools of Thought. Current Urban Studies, 7, 562-572. https://doi.org/10.4236/cus.2019.74029

Spangenberg, J. H., Pfahl, S., \& Deller, K. (2002). Towards Indicators for Institutional Sustainability: Lessons from an Analysis of Agenda 21. Ecological Indicators, 2, 61-77. https://doi.org/10.1016/S1470-160X(02)00050-X

Speck, L. (2014). The Importance of Mixed Use. The 2014 Symposium of Sustainability on the UT Campus, Short Essay.

https://sustainability.utexas.edu/sites/sustainability.utexas.edu/files/0201_Speck_Symp osium2014.pdf

Valentin, A., \& Spangenberg, J. H. (2000). A Guide to Community Sustainability Indicators. Environmental Impact Assessment Review, 20, 381-392. https://doi.org/10.1016/S0195-9255(00)00049-4

Willis, A. J. (1997). The Ecosystem: An Evolving Concept Viewed Historically. Functional Ecology, 11, 268-271. https://doi.org/10.1111/j.1365-2435.1997.00081.x

Wilson, E. O. (1992). The Diversity of Life. Cambridge, MA: Harvard University Press.

Xie, L., Cheshmehzangi, A., Tan-Mullins, Flynn, A., \& Heath, T. (2020). Urban Entrepreneurialism and Sustainable Development: A Comparative Analysis of Chinese Eco-Development. Journal of Urban technology, 27, 3-26. https://doi.org/10.1080/10630732.2019.1680940

Zamorano, L., \& Kupla, E. (2014). People-Oriented Cities: Mixed-Use Development Creates Social and Economic Benefits.

https://www.wri.org/blog/2014/07/people-oriented-cities-mixed-use-development-crea tes-social-and-economic-benefits

Zhang, J. (2005). Shaping the Pattern: A Historical Perspective on the Interaction between Space and Function in Clerkenwell. Proceedings of the 5th International Space Syntax Symposium, 2, 635-653. 